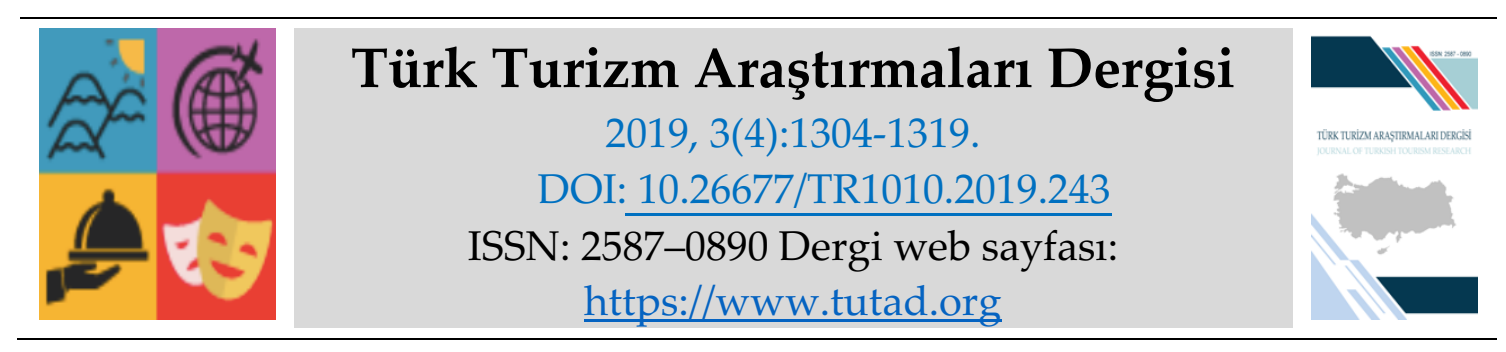

ARAȘTIRMA MAKALESI

\title{
Etkinliklerin Öteki Yüzü: Olimpiyat Oyunları Örneği
}

Can KAHRIMAN, Çanakkale Onsekiz Mart Üniversitesi, Sosyal Bilimler Enstitüsü, Çanakkale, e-posta: cankahriman.ck@gmail.com

ORCID: https://orcid.org/0000-0001-8228-9976

Dr. Öğr. Üyesi Hacı Mehmet YILDIRIM, Çanakkale Onsekiz Mart Üniversitesi, Turizm Fakültesi, Çanakkale, e-posta: hadjimehmet@gmail.com

ORCID: https://orcid.org/0000-0003-0718-7296

Öz

Özellikle destinasyonların tanıtım ve pazarlama faaliyetlerine önemli katkılar sağlayan olimpiyat oyunları uzun yıllar ülkelerin imaj yaratma çabalarında öne çıkan bir etkinlik türü olmuştur. Ayrıca olimpiyat oyunları sayesinde gelişen alt ve üst yapı faaliyetleri destinasyonlara olumlu katkılar sağlamaktadır. Fakat ev sahibi ülkelere yüklenen maddi sorumluluklar, tesislerin oyunlar sonrasında atıl kalması ve son yıllarda olimpiyat oyunlarının beklentileri tam anlamıyla karşılamaması olimpiyat oyunlarının yeniden değerlendirilmesi gerekliliğini ortaya çıkarmıştır. $\mathrm{Bu}$ çalışmada, olimpiyat oyunlarının olumlu etkilerinden ziyade olumsuz yönlerinden de bahsedilerek olimpiyatların diğer etkilerini ortaya koymak amacıyla yapılmıştır. Bu amaçla, Londra (2012), Rio (2016) ve Sochi (2014) olimpiyat oyunlarının incelendiği çalışmada arşiv tarama doküman analizi yöntemi kullanılarak olimpiyat oyunları ile ilgili web sayfaları, yıllık raporlar ve ilgili makaleler incelenmiştir. Çalışma sonunda olimpiyat oyunlarının olumsuz etkilerinin göz ardı edilmemesi gerekliliği ortaya çıkmıştır.

Anahtar Kelimeler: Olimpiyat Oyunları, Londra, Sochi, Rio, Etkinlik, Etkinliklerin Olumsuz Etkisi.

Makale Gönderme Tarihi: 21.05.2019

Makale Kabul Tarihi: 02.10.2019

\section{Önerilen Atıf:}

Kahriman, C. ve Yıldırım, H. M. (2019). Etkinliklerin Öteki Yüzü: Olimpiyat Oyunları Örneği, Türk Turizm Araştırmaları Dergisi, 3(4): 1304-1319.

(c) 2019 Türk Turizm Araştırmaları Dergisi. 


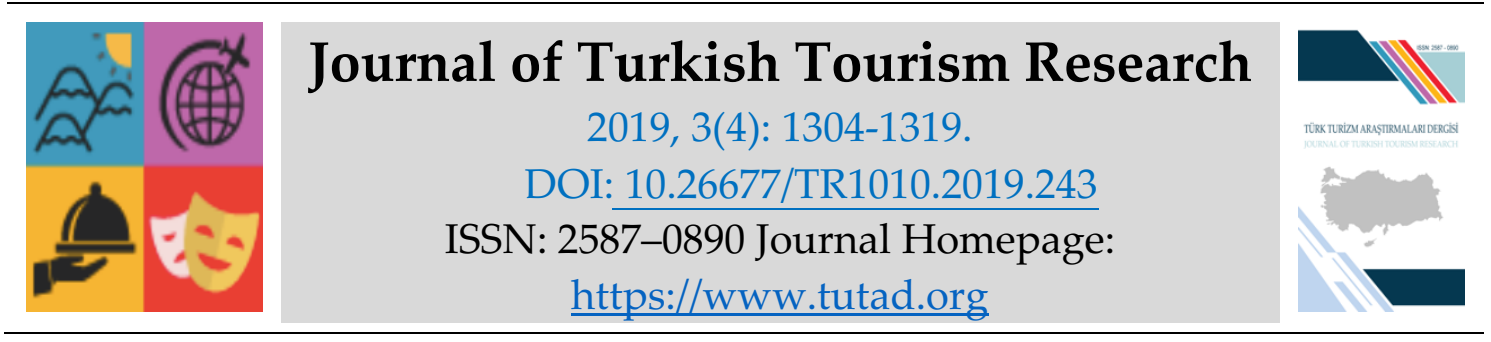

\title{
$\underline{\text { RESEARCH PAPER }}$
}

\section{The Other Face of Events: The Case of Olympic Games}

Can KAHRIMAN, (MSc.) Çanakkale Onsekiz Mart University, Social Sciences Institute, Çanakkale, e-mail: cankahriman.ck@gmail.com

ORCID: https://orcid.org/0000-0001-8228-9976

Assistant Prof. Dr. Hacı Mehmet YILDIRIM, Çanakkale Onsekiz Mart University, Tourism Faculty, Çanakkale, e-mail: hadjimehmet@gmail.com

ORCID: https://orcid.org/0000-0003-0718-7296

\begin{abstract}
The Olympic Games which have made significant contributions to the promotion and marketing activities of the destinations has become a prominent event in countries' efforts to create an image for many years. Also, developing thanks to Olympic Games, infrastructure and superstructure activities provide positive contributions to destinations. However, the financial responsibilities imposed on the host countries, the idle of the facilities after the games, and the fact that the Olympic Games did not fully meet the expectations in the recent years revealed the necessity of re-evaluating the Olympic Games. Therefore, this study is carried out in order to reveal the other effects of the Olympics by mentioning the negative aspects of the games rather than the positive effects of the Olympic games. For this purpose, in this study examining London, Rio and Sochi Olympic Games was analyzed web pages, annual reports and related articles by using archivedocument analysis. The result of this study, it was revealed that the negative effects of Olympic games should not be ignored.
\end{abstract}

Keywords: Olympic Games, London, Sochi, Rio, Event, Negative Impact of Events. Received: 21.05.2019

Accepted: 02.10.2019

\section{Suggested Citation:}

Kahriman, C. and Yıldırım, H. M. (2019). The Other Face of Events: The Case of Olympic Games, Journal of Turkish Tourism Research, 3(4): 1304-1319.

(c) 2019 Türk Turizm Araştırmaları Dergisi. 


\section{Gíriş}

Turizm sektörünün bileşenlerinden biri olan etkinlik endüstrisi birçok uluslararası destinasyon için değerli ekonomik, sosyal ve kültürel faydalar sağlayarak turizmde potansiyel bir büyüme imkânı sunar (Dickson ve Arcodia, 2015). Metropollerde yaşayan bireyler, kalabalık kent yaşamından kaçmak istemekte ve bu doğrultuda turizm ve rekreasyon faaliyetlerine katılım göstermektedirler. Düzenlenen etkinlikler, turistleri destinasyona çekerek bölgedeki turizm hareketliliğinin artmasına neden olmaktadır (Can, 2015). Etkinlikler, birçok uluslararası destinasyon için değerli ekonomik, sosyal ve kültürel faydalar sağladığından ve turizmde potansiyel büyümeye yol açtığından turizm endüstrisinin önemli bir bileşenidir (Dickson ve Arcodia, 2010; Erdem vd., 2018).

Turistler için önemli bir çekicilik unsuru olan etkinlikler, bir destinasyonun turistler tarafından ziyaretine olanak sağlamak için düzenlenirler (Çelik, 2009). Bunun yanı sıra etkinlikler hem turizme hem de turizmin etkilediği toplulukların sosyal ve ekonomik sürdürülebilirliğine önemli katkılar sunmaktadır (Dodds ve Walsh, 2018). Ayrıca etkinliklerin bir diğer olumlu etkisi ise kültürel değerleri tanıtma, kentin tutundurulması, şehre turist çekilmesi ve yerel halk için eğlence olanakları oluşturarak destinasyondaki yaşam kalitesini arttırmaktır (Yolal, 2017). Bu bağlamda gerçekleştirilen etkinlikler destinasyonlar üzerinde önemli etkilere sahiptirler. Buna karşıllık, etkinliklerin bir destinasyon üzerinde yapmış olduğu etkiler sadece olumlu yönde gelişmemiştir. Olumlu etkileri olduğu kadar olumsuz etkileri de bulunmaktadır. Bu etkiler; sosyo- ekonomik, sosyo- kültürel, fiziksel ve politik olarak boyutlandırılırlar (Malfas, Theodoraki ve Houlihan, 2004; Kızılırmak, 2006). Sosyal açıdan istihdam olanağı sağlarken aynı zamanda adaletsiz gelir dağılımına, çevreye olan ilginin artmasıyla atık ve kirliliğin oluşmasına, ekonomik anlamda da iş ve ticaret hacminin gelişmesine olanak sağlarken artan ürün fiyatlarını da beraberinde getirebilir.

Etkinliklerin bir türü olarak olimpiyatlar düzenlendikleri destinasyonlar açısından önemli etkilere sahiptir. Ekonomik ve sosyal açıdan olumlu etkilerinin yanı sıra olumsuz etkileri de bulunmaktadır. Ayrıca olimpiyat oyunlarının düzenlendiği destinasyonlara sağladığı olumlu katkıların yanı sıra bu katkıların sürdürülebilirliği açısından olimpiyat oyunları çeşitli eleştirilerle karşı karşıya kalmaktadır (Matheson ve Baade, 2004). Bu çalışmanın amacı, etkinliklerin olumlu etkilerinden ziyade olumsuz yönlerinden bahsederek etkinliklerin diğer etkilerini ortaya koymaktır. Bu amaç doğrultusunda, mega etkinliklerden olan olimpiyat oyunlarının ev sahibi şehre ve destinasyona yapmış olduğu etkiler incelenmiştir.

\section{KAVRAMSAL ÇERÇEVE}

\section{Etkinlikler ve Etkileri}

Etkinlik, belirli bir amaç için insanların uyarıldığı ve birlikte o amaç uğruna hareket edilen faaliyettir. Festivaller, konserler, olimpiyatlar, uluslararası organizasyonlar ve sosyal sorumluluk projeleri bunlara örnek olarak verilebilir. Etkinlikler, önemli bir turistik çekicilik unsuru olduğundan dolayı bir destinasyonun turistler tarafından ziyaret edilmesini ve güzel zaman geçirmelerini sağlamak amacıyla düzenlenirler.

Etkinlikler, ölçeklerine ve konularına göre sınıflandırılabilirler. Ölçeğe göre etkinlikler dört gruba ayrılmaktadır. Bunlar mega, hallmark, bölgesel ve yerel etkinliklerdir. Mega etkinlikler, Olimpik Oyunlar, Paralimpik Oyunlar, FIFA Dünya Kupası, Dünya Atletizm Şampiyonası ve Dünya Fuarları gibi ülke ekonomisini ve imajını etkileme gücüne sahip olan etkinlikler olarak 
nitelendirilmektedir (Timur vd., 2014). Ölçeklerine göre etkinlikler yapılma amaçlarına ve geliştirme koşullarına göre Tablo 1'de gösterilmektedir.

Tablo 1. Amaçlarına Göre Etkinlikler ve Amaçları

\begin{tabular}{|c|c|c|}
\hline Etkinlik Türü & Amaçları & Geliştirme Koşulları \\
\hline $\begin{array}{l}\text { Mega Etkinlikler } \\
\text { - Olimpiyatlar } \\
\text { - Dünya Çapındaki Fuarlar } \\
\text { - Spor Etkinlikleri }\end{array}$ & $\begin{array}{l}\text { - İmaj oluşturma } \\
\text { - Yabancı turist ve buna } \\
\text { bağlı olarak gelir artışı } \\
\text { - Yeni tesisler } \\
\text { - Konuya İlgiyi arttırma }\end{array}$ & $\begin{array}{l}\text { - Rekabet } \\
\text { - Uzun dönemli planlama } \\
\text { - Alt ve üstyapı } \\
\text { düzenlemeleri } \\
\text { - Sponsorluklar }\end{array}$ \\
\hline $\begin{array}{l}\text { Bölgesel Etkinlikler } \\
\text { - Festival } \\
\text { - Spor } \\
\text { - Fuar }\end{array}$ & $\begin{array}{l}\text { - Mega etkinliğe benzer } \\
\text { fakat ulusal ve yurtiçi } \\
\text { pazar için daha ilgi çekici } \\
\text { - Uzun dönemli büyüme ve } \\
\text { etkileri uzun döneme } \\
\text { yaymak }\end{array}$ & $\begin{array}{l}\text { - Sürdürülebilirlik ve birlikte } \\
\text { pazarlama } \\
\text { - Mekanların kalıcılığı }\end{array}$ \\
\hline $\begin{array}{l}\text { Yerel Etkinlikler } \\
\text { - Yerel festivaller } \\
\text { - Yarışmalar } \\
\text { - Panayırlar }\end{array}$ & $\begin{array}{l}\text { - Yerel kalkınmayı sağlamak } \\
\text { - Yerel olarak ilgi } \\
\text { oluşturmak ve turistlere } \\
\text { alternatif sunmak }\end{array}$ & $\begin{array}{l}\text { - Gönüllülük esası } \\
\text { - Kalıcı tesis yerine geçici tesis } \\
\text { kurma } \\
\text { - Pazarlama desteği ile } \\
\text { tanınırlığı arttırma }\end{array}$ \\
\hline
\end{tabular}

Kaynak: Getz, 1997: 104.

Etkinlikler, yapıldıkları bölgenin imajını yaratma ve bu imajın uluslararası düzeyde pazarlanmasında kullanılmaktadır. Birçok ülke, şehir ve kasaba festivaller, konserler, olimpiyatlar ya da uluslararası organizasyonlar ile bunu gerçekleştirmektedir. Bu bağlamda etkinlikler, destinasyonların gelişiminde, imaj oluşturmada ve turistik çekiciliklerin tanıtılmasına katkı sağlamaktadırlar.

Etkinliklerin turizmi teşvik ettirdiğini, destinasyonların pazarlanmasında ve gelişiminde önemli bir yeri olduğuna değinen Getz (2008), etkinlikleri; planlı ve plansız olmak üzere iki şekilde gruplandırmaktadır. Hazırlığı önceden yapılmış planlı etkinlikler; kültürel kutlamaları, sanat ve eğlence etkinliklerini, spor etkinliklerini, eğitim ve bilimsel amaçlı etkinlikleri, rekreasyonel vb. etkinlikleri kapsamaktadır. Aynı zamanda Getz, yapılan planlı etkinliklerin destinasyonlar arasındaki rekabetin öneminin kanıtlandığını belirtmektedir. Etkinliklerin, ulusal kimliğe, imaja ve kentsel yenilenmeye yaptığı katkılarla turizmde önemli bir rol oynamaktadır (Getz, 2008).

Olimpiyatlar gibi büyük etkinliklere ev sahipliği yapmak organizasyonun markasının kullanılması ile ev sahibi şehre küresel anlamda saygınlığını arttırma ve uluslararası rekabette ön plana çıkma şansı verir (Kaplanidou, 2006; Rocha ve Fink, 2017). Aynı zamanda ev sahibi şehrin ekonomisinin ve altyapı hizmetlerinin iyileştirilip geliştirilmesinde önemli bir unsur olarak görülmektedir (Essex ve Chalkley, 1998; Malfas vd., 2004; Matheson ve Baade, 2004).

Önemli spor etkinliklerine ev sahipliği yapmanın etkisi, ev sahibi şehir ve ülkedeki gelişim düzeyine göre değişir. Doğru planlama ile büyük bir etkinliğe ev sahipliği yapmak, genellikle az gelişmiş alanlara daha fazla fayda sağlayarak modern ulaşım, iletişim ve spor altyapısının inşası için bir katalizör görevi görebilir (Essex ve Chalkley, 1998; Zimbalist, 2010). 
Büyük bir spor etkinliğine ev sahipliği yapmak hem doğrudan hem de dolaylı olarak ekonomik faydalar sağlamaktadır. Doğrudan ekonomik faydalar sermayeyi yani oyunlar için yapılacak olan altyapı çalışmalarını ve turistlerin oyunlara ulaşabilmesi için yapılan harcamaları içerir. Dolaylı ekonomik faydalar arasında ise, gelecekteki potansiyel turistleri, ev sahibi şehrin reklamlarının yapılarak imajına katkı sağlanmasını ve yerel halkın kendilerine olan güvenlerinin artmasını kapsar. Ancak büyük bir etkinliğe ev sahipliği yapmanın muhtemel maliyet aşımları, kötü arazi kullanımı, yetersiz planlama ve yetersiz tesislerden kaynaklanan potansiyel bir dezavantajı da bulunmaktadır (Zimbalist, 2010).

Büyük spor organizasyonlarına ev sahipliği yapmak şehir ve bölgeye birçok açıdan olumlu etki yarattığı konusunda hemfikir olunduğu ancak buna karşın yaratılan ekonomik etkiler açısından farklı görüşlerin olduğu görülmektedir (Matheson ve Baade, 2004; Owen, 2005; Horne ve Manzenreiter, 2006). Büyük spor etkinliklerinden olan olimpiyatlar oldukça fazla altyapı ve tesis maliyeti gerektiren bir organizasyon olduğu için çoğu zaman sadece başa baş noktasına ulaşabilmiştir (Essex ve Chalkley, 1998). 2014 Sochi Kış Olimpiyat Oyunlarında, spor tesislerin sıfırdan inşa edilmesinin Rus hükümetine 16 milyar \$'lık bir maliyeti olmuştur. Bunun yanı sıra yine Sochi' de olimpiyat oyunlarının yapılacağı bölgeye turistlerin ve sporcuların gidebilmesi için yapılan altyapı harcamaları spor için yapılan masrafın da önüne geçerek Rusya'ya 38,8 milyar \$'llk bir maliyete neden olmuştur (Müller, 2014).

Etkinliklerin bir destinasyon üzerinde yaptığı etkiler sadece olumlu yönde gelişmemiştir. Olumlu etkileri olduğu kadar olumsuz etkileri de bulunmaktadır. Bu etkiler; sosyo- ekonomik, sosyokültürel, fiziksel ve politik olarak boyutlandırılırlar (Malfas, Theodoraki ve Houlihan, 2004; Kızllırmak, 2006). Bunlardan sosyo-kültürel olumsuz sonuca, toplumun yabancılaşması ve olumsuz toplumsal imaj, politik olumsuz sonuca ise faaliyetlerin başarısız olma riski örnek olarak verilebilir. Etkinliklerin aynı zamanda sosyal, çevresel ve ekonomik etkileri de bulunmaktadır. Bu etkiler Tablo 2'deki gibidir.

Tablo 2'ye göre, etkinliklerin sosyal anlamda iş olanaklarını artırma, toplumsal kalkınmayı destekleme gibi olumlu etkileri varken, buna karşılık olarak toplumsal yaşam tarzının bozulması ve adaletsiz gelir dağılımının oluşmasına neden olabilir. Aynı zamanda yaşanılan yere hayranlık duyulmasını sağlayarak çevresel ilgiyi arttırır. Ancak bu durum beraberinde atık ve kirlilik, gürültü kirliliği oluşmasına ve enerji kaynaklarının kullanımında talep artışı yaşanmasına neden olur. Ekonomik anlamda ise, etkinliği uygulamak için yapılan harcamalar doğrultusunda etkinliğin başarısız olma ihtimalinin ülke ekonomisine yaratacağı maliyet bir külfet olarak ortaya çıkmaktadır.

\section{Modern Olimpiyat Oyunları}

Olimpiyat oyunları, Yunanistan'da uzun yıllar boyunca süregelen savaşlarla birlikte birbirinden ayrılmış olan şehirlerin yeniden birleşmesi ve bir arada olmaları amacıyla düzenlenmiş bir festival olarak başlamıştır (Doralp ve Barkul, 2011). Yunanistan'daki Olimpia bölgesinde yapıldığı için adını buradan alan olimpiyat oyunlarının ne zaman başladığı kesin olarak bilinmemekle birlikte M.Ö. 776 yılına kadar dayandığı söylenmektedir (Chalkey ve Essex, 1999; Tekin 2014; Ak 2015).

Antik Olimpiyat Oyunları'nı temel alarak gerçekleştirilen ilk oyunlar 1796-1798 yıllarında Fransa' daki ulusal bir festival olan L'Olympiade De La Republique olmakla birlikte, Yunanistan, 1829 ' da Osmanlı İmparatorluğu'nun etkisinden kurtulup özgürlüklerini kazanmaları sonrasında oyunları yeniden canlandırmak istemiş, Evangelis Zappas 1833 yılında olimpiyat oyunu benzeri bir etkinliğin yapılmasını teklif etmiştir. 1859 yılında Yunanistan'dan ve Osmanlı 
İmparatorluğu'ndan gelen atletler ile birlikte Atina şehir meydanında ilk Modern Olimpiyat Oyunları düzenlenmiştir (Doralp ve Barkul 2011). Gerçek anlamda günümüzdeki gibi yapılan Modern Olimpiyat Oyunları'nın kurucusu ise Fransız tarihçi Baron Pierre De Coubertin'dir (Chalkey ve Essex 1999; Balmer vd., 2003; Malfas, vd., 2004; Yıldız ve Aydın 2013; Tekin ve Tekin, 2014).

Tablo 2. Etkinliklerin Etkileri

\begin{tabular}{|c|c|c|}
\hline & Olumlu & Olumsuz \\
\hline Sosyal Etkiler & $\begin{array}{l}\text { - Kalkınmayı, altyapı ve } \\
\text { üstyapı harcamalarını teşvik } \\
\text { etme } \\
\text { - Tanıtıma katkı } \\
\text { - Yaşanılan yere hayranlık } \\
\text { duyulmasını sağlama } \\
\text { - Toplumsal kalkınmayı } \\
\text { destekleme } \\
\text { - İş olanaklarını artırma }\end{array}$ & 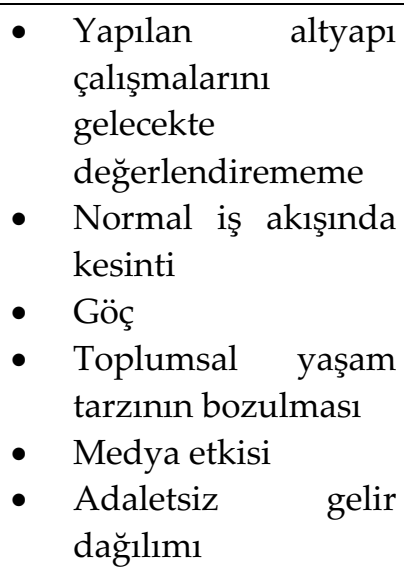 \\
\hline Çevresel Etkiler & $\begin{array}{ll}\text { - } & \text { Çevresel ilginin artması } \\
\text { - } & \text { Atıl bölgelerin gelişiminin } \\
\text { sağlanması } \\
\text { - } & \text { Alanların } \\
& \text { sürdürülebilirliğinin } \\
& \text { sağlanması }\end{array}$ & $\begin{array}{ll}\text { - } & \text { Etkinlik alanına } \\
& \text { verilen zarar } \\
\text { - } & \text { Atıklar ve kirlilik } \\
\text { - } & \text { Gürültü kirliliği } \\
\text { - } & \text { Enerji ve diğer } \\
& \text { kaynak } \\
\text { kullanımlarında } \\
\text { artan talep }\end{array}$ \\
\hline Ekonomik Etkiler & $\begin{array}{ll}\text { - } & \begin{array}{l}\text { Doğrudan ve dolaydı } \\
\text { harcama }\end{array} \\
\text { - } & \text { Gayrimenkul değerinde } \\
& \text { artış } \\
\text { - } & \text { İş ve ticarette gelişim } \\
\text { - } & \text { Kalkınma ve yapısal } \\
& \text { harcamaları teşvik etme }\end{array}$ & 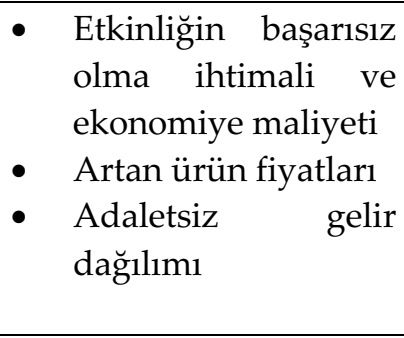 \\
\hline
\end{tabular}

Kaynak: Raj ve Musgrave, 2009: 5.

1896 yılında Atina'da düzenlenen gerçek anlamdaki ilk modern olimpiyatlardan itibaren, adil ve barış̧̧ıl bir rekabet anlayışı ile düzenlenmeye devam eden olimpiyat oyunları zaman içinde ülkelerin ekonomik, siyasi, bilimsel ve kültürel alanlarda güçlerini gösterebildiği organizasyonlar olarak giderek artan ölçüde ilgi görmüştür (Yıldız ve Aydın 2013).

Olimpiyatların 19. yüzyılın sonlarında yeniden canlandırılmasından bu yana, olimpiyat oyunları dünyanın en büyük spor etkinliği olmaya başlamıştır (Malfas vd., 2004). Olimpiyat oyunlarının büyüklüğü ve önemi ev sahibi şehirlerin alt yapısı için büyük zorluklar ve fırsatlar yaratır. 1896 yılında Atina'da düzenlenen ilk modern oyuna 13 ülkeden toplam 311 sporcu katılmıştır (sporcuların 230'u Yunan). 1996'da Atlanta'da, 196 ülkeden 10.788 sporcu katılmıştır. Oyunların 
artan boyutu, ev sahibi şehirler için spor tesislerinin yapılmasının ve sporcular için etkinlik düzenlenmesinin ötesine uzanan sonuçlar doğurmuştur. Geliştirilmiş havalimanı kapasitesi, konaklama, toplu taşıma, altyapı ve üst yapı sistemleri ve çevresel düzenleme gibi yapılan yatırımlar, oyunların etkin bir şekilde işletilmesini ve mümkün olan en iyi imajı seyircilere sağlamak için gerekli olmuştur. Bu yüzden yüzyıl boyunca, oyunlar bir spor yarışmasından çok daha fazlasını sunmuştur ve geliştirmiştir. Ana katılımcı ülkeler için, ulusal prestij arayışı haline gelmiştir. Ev sahibi şehirler de bunu uluslararası öneme sahip olmak için bir araç olarak kullanmışlardır (Chalkley ve Essex, 1999).

Olimpiyatlar oyunları kısa dönemli ve geçicidir; fakat olimpiyatların ev sahibi şehre bıraktığı miraslar kentin geleceğini etkilemektedir. Bu da olimpiyatları cazip hale getiren en büyük etkendir. Ev sahibi olan şehir eline geçen bu fırsatı iyi bir şekilde değerlendirebilirse başta ekonomik olmak üzere birçok kazanç sağlama imkânı sağlayabilir. Fakat ev sahibi olan şehir açısından önemli katkıları bulunan olimpiyat oyunları diğer taraftan birçok kent sakininin tepkisi ile karşılaşmaktadır. Bunun nedeni ise vaat edilen etkilerin gerçekleşmemesi ve kentte yarattığ1 olumsuz sonuçlardır (Ak, 2015).

Tüm bu anlatılanlardan hareketle; çok eski zamanlardan beri yapılan bir etkinlik olan olimpiyat oyunlarını düzenlemek ev sahibi şehirler için olimpiyat markasından dolayı cazip gelmektedir. Mega bir etkinlik olan olimpiyat sosyal, çevresel ve ekonomik etkileri içinde barındırmaktadır. Bu bağlamda kentler için söz konusu olan etkiler çalışmanın diğer bölümlerinde anlatılmaktadır.

\section{YÖNTEM}

Araştırmanın içeriğini oluşturan çalışmalara literatür taraması sonucu ulaşılmıştır. Çalışmada nitel veri toplama yöntemlerinden arşiv taraması ve doküman analizi teknikleri kullanılmıştır. Geçmişe dönük her türlü sözlü ve yazılı kayıtlar arşiv ve doküman taramasını oluşturmaktadır. Teknolojinin gelişmesi ile birlikte önemi giderek artan arşiv-doküman taramasından elde edilen yardım sayesinde, konunun geçmişe dönük derinlemesine araştırılması ve dönem içinde meydana gelen değişim analiz edilerek resmin bütününe ulaşılması mümkün olmaktadır (Kozak, 2015). Büyük örneklem elde etme imkanının ortaya çıkması ve nitel araştırmalardaki genelleme probleminin çözümüne katkı sağlayabilmesinden dolayı doküman analizi tekniği kullanılmıştır (Karagöz, 2017). Arşiv taraması ve doküman analizi, Uluslararası Olimpiyat Komitesi (IOC) tarafından yayınlanan yıllık raporları, olimpiyatlar ile ilgili gazete haberlerini ve internet sitelerini kapsamaktadır. Araştırmanın örneklemini 2012-2016 yılları arasında gerçekleştirilen: Londra (2012), Sochi (2014) ve Rio (2016) olimpiyat oyunları oluşturmaktadır. Son dönemde yapılan olimpiyat oyunlarında maliyetlerin tahmin edilen bütçelerin üzerinde çıkmasından dolayı seçilen oyunlar çalışmanın örneklemini oluşturmaktadır.

\section{ETKINNLIKKLERINN ÖTEKİ YÜZÜ: OLIMPIYAT OYUNLARI ÖRNEĞİ}

Büyük spor etkinlikleri, ev sahibi şehir ve ülkedeki gelişim düzeyine göre değişir. Doğru planlama ile büyük bir etkinliğe ev sahipliği yapmak, genellikle az gelişmiş alanlara daha fazla fayda sağlayarak modern ulaşım, iletişim ve spor altyapısının inşası için bir katalizör görevi görebilir (Essex ve Chalkley, 1998; Zimbalist, 2010).

Büyük bir spor etkinliğine ev sahipliği yapmak hem doğrudan hem de dolaylı olarak ekonomik faydalar sağlamaktadır. Doğrudan ekonomik faydalar sermayeyi yani oyunlar için yapılacak olan altyapı çalışmalarını ve turistlerin oyunlara ulaşabilmesi için yapılan harcamaları içerir. Dolaylı ekonomik faydalar arasında ise, gelecekteki potansiyel turistleri, ev sahibi şehrin 
reklamlarının yapılarak imajına katkı sağlanmasını ve yerel halkın kendilerine olan güvenlerinin artmasını kapsar. Ancak büyük bir etkinliğe ev sahipliği yapmanın muhtemel maliyet aşımları, kötü arazi kullanımı, yetersiz planlama ve yetersiz tesislerden kaynaklanan potansiyel bir dezavantajı da bulunmaktadır (Zimbalist, 2010).

Maliyet aşımları, büyük ve mega projeler için ortak bir olgudur. İhale aşamasında, Uluslararası Olimpiyat Komitesi (IOC), kamu harcamalarının ve bunun sonucunda elde edilen ekonomik faydaların analizini gerçekleştirmelidir. Uluslararası Olimpiyat Komitesi'nin yalnızca maliyet aşımları konusundaki göstereceği şeffaflık, kontrol edilemeyen olimpiyat oyunları maliyetleri ile ilgili eleştirilerin dikkate alınmasına yardımcı olacaktır.

Proje uygulamalarındaki gecikmeler ve maliyet aşımları kamu sektörü projeleri için sürekli sorun olmuştur (Satyanarayana 1974'den aktaran Preuß, vd., 2019:8). Maliyet aşımları üzerine yapılan çalışmalar genel olarak altyapı projeleri ile ilgilidir. Altyapı projeleri genel olarak kamu parası ile finanse edilmektedir. Bununla birlikte, literatür, etkinlikler veya olimpiyat oyunları gibi organizasyonel projelere yönelik araştırmalardan yoksundur (Preuß, vd., 2019). Maliyet aşımına neden olan faktörler Tablo 3'te gösterilmektedir.

Tablo 3. Maliyet Aşımına Neden Olan Faktörler

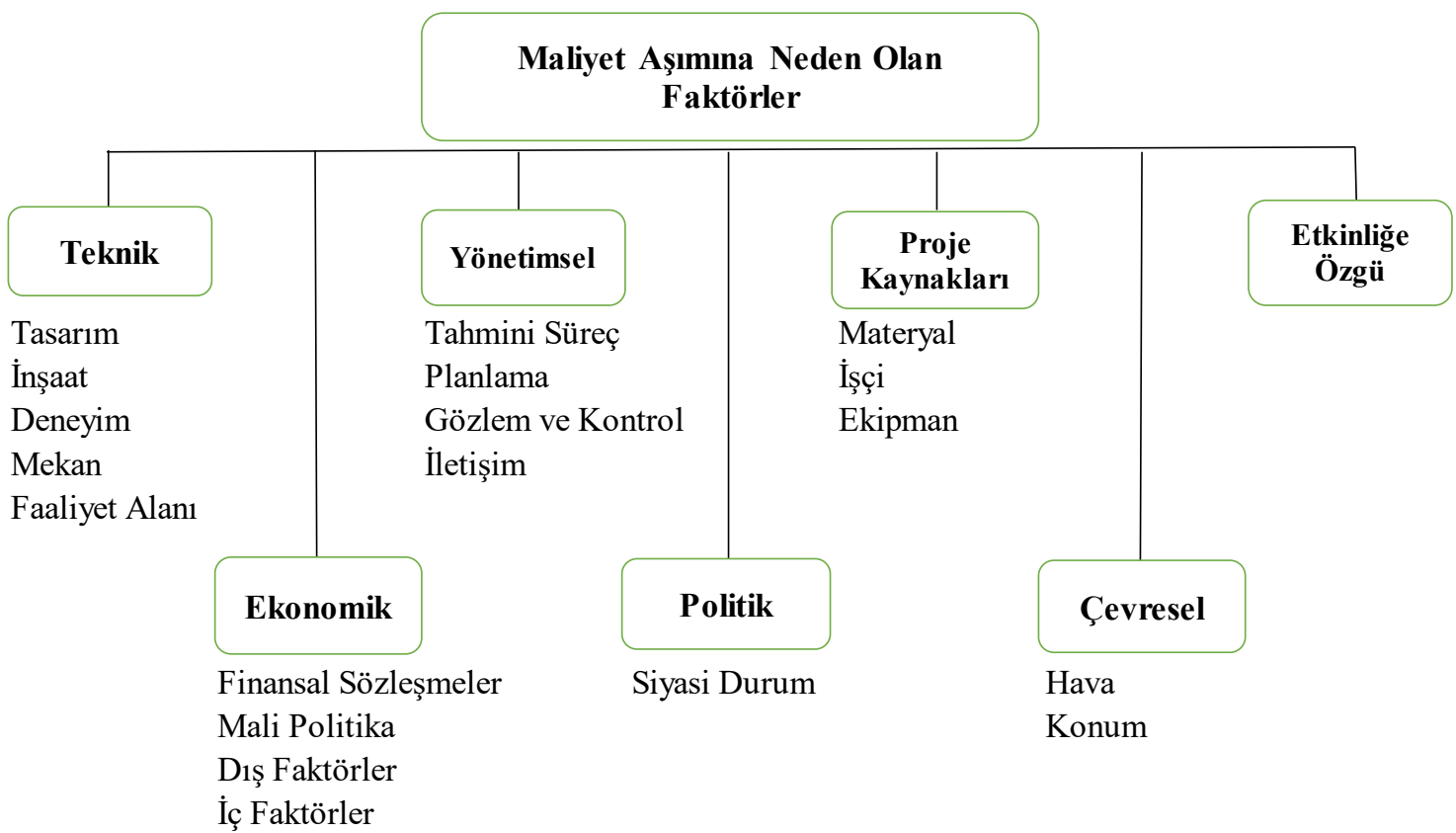

Kaynak: Preuss, Andreff ve Weitzmann, 2019: 8.

Maliyet aşımına neden olan birçok faktör vardır. Genel faktörler teknik, ekonomik, yönetimsel, politik, proje kaynakları, çevresel ve etkinliğe özgü olarak sınıflandırılmaktadır.

Teknik kaynaklı maliyet aşımları tasarım, inşaat, deneyim, mekân ve faaliyet alanı olarak kategorileştirilmektedir. Olimpiyat gibi çok sayıda değişkeni bir araya getiren böylesine büyük organizasyonu düzenleme konusunda çoğu ülke deneyimsizdir. Organizasyonda yapılacak en ufak hatanın diğer projeleri de etkilemesi mümkündür (Müller, 2015:632). Bu nedenle mega etkinlikler maliyet aşımına eğilimlidir. Olimpiyat oyunlarının sahneleneceği yerler, buraların tasarımı ve diğer mekanların (konaklama, yol, sporcu köyü vb.) maliyetleri, projelerin 
büyüklügünden dolayı belirlenen maliyetlerin üzerine çıkarak maliyet aşımına sebep olmaktadır (Flyvbjerg ve Stewart, 2012; Orttung ve Zhemukhov, 2014).

Ekonomiye dayalı maliyet aşımlarına finansal sözleşmeler, mali politikalar ve iç ve dış faktörler neden olmaktadır. Finansal yükleniciler en düşük fiyatı seçme eğilimindedirler ve bu kişilerin deneyim eksikliğine bağlı olarak yönetimdeki zayıflıkları fiyat artışlarına neden olmaktadır. Ayrıca, verilen kötü yatırım kararları, yetersiz finansman ve bitmiş projeler için yaşanan ödeme problemleri finansal politika alanındaki yüksek maliyete neden olan faktörlerden bazılarıdır.

Maliyet aşımı ile ilgili diğer başlıkları birleştirecek olursak, etkinliğin kendisini yürütme maliyetleri yani en fazla maliyete neden olan harcamaları personel maaşları, bilgi teknoloji ekipmanları, ulaşım, geçici mekân yerleşimi, delegasyonların konaklaması ve törenler oluşturmaktadır. Etkinliğin işleyişi ise Olimpiyat Oyunları Organizasyon Komitesi (OCOG) sorumluluğundadır. Fakat tüm maliyetler OCOG bünyesinde yer almamaktadır. Güvenlik maliyetleri OCOG bünyesinde olmayan maliyetlerden biridir. Rusya'da gerçekleşen 2014 Sochi kış olimpiyat oyunlarında yaklaşık 1,92 milyar \$'a mal olan güvenlik maliyeti OCOG bünyesinde yer almadığı için hükümetin üstlenmesi gereken bir maliyet olmuştur (Müller, 2014). Güvenlikte çıkan yüksek maliyet olimpiyat oyunları için yapılan hazırlıklarda güvenliğin önemini yansıtmaktadır. Oyunlarda ortaya çıkan diğer maliyet kalemleri sporla ilgi olan; IOC tarafından talep edilen tüm etkinliklere bağlı binaların, mahallerin, olimpiyat köylerinin, spor salonlarının ve medya merkezlerinin kurulması oluştururken, sporla ilgili olmayanları yollar, havaalanlarının genişletilmesi, oteller vb. yapılar oluşturmaktadır.

Olimpiyat oyunlarının maliyetleri ve faydaları, oyunlar başlamadan önce, başladığında ve oyunlar bittikten sonra devam eden tartışma konularıdır. Olimpiyat oyunlarının ev sahibi şehre gerçek maliyetini öğrenmek IOC'nin harcamaları ayrıntılı bir şekilde paylaşmamasından dolayı kısıtlı bir bilgidir (Orttung ve Zhemukkov, 2014). Maliyetlerin ayrıntılı bir şekilde paylaşılmamasının sebebi ise, halkın bu durumdan dolayı etkinliğe vereceği desteğin azalma ihtimalidir (Cashman, 2002).

Grafik 1. Ayrılan Bütçe ve Maliyet

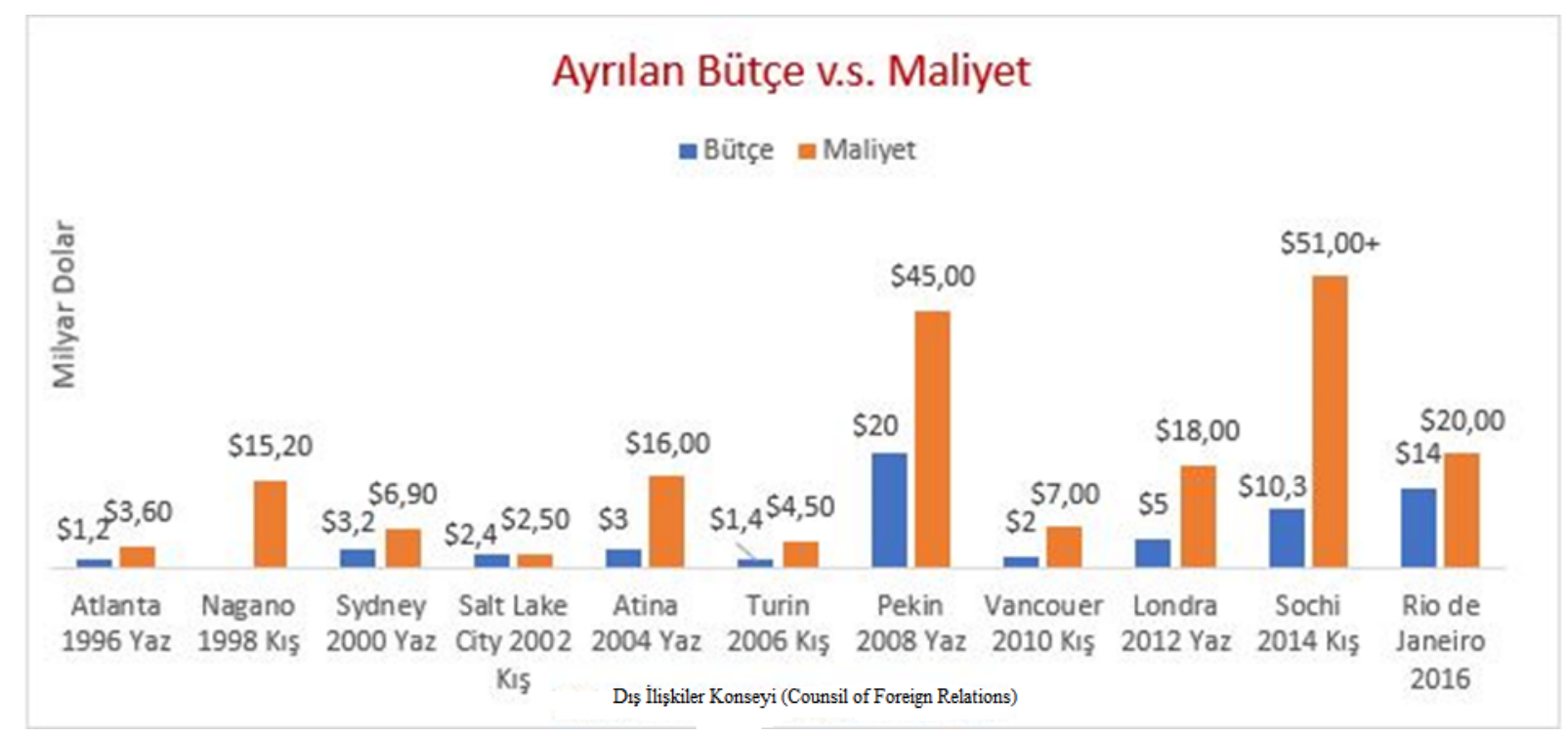

Kaynak: Greenberg ve Daniel, 2017 
Ülkelerin ve şehirlerin olimpiyat oyunlarında alt ve üst yapı hizmetleri için ayırdıkları bütçe çoğu zaman aşılmıştır. Aşılan bu bütçeler ve beklenen faydanın sağlanamaması ülke ekonomilerini olumsuz yönde etkilemektedir. Olimpiyat oyunlarında ülkelerin ayırdıkları bütçe ve karşılaştıkları maliyet Grafik 1'de gösterilmektedir.

Ülkeler ve şehirler için olimpiyat oyunlarına ev sahipliği yapmak avantajlı olarak görülse de oyunlar için ayrılan bütçe ve maliyet karşılaştırıldığında sadece birkaç şehrin başa baş noktasına ulaştığ1 görülmektedir. Araştırmanın örneklemini oluşturan Londra (2012), Rio (2016) Yaz Olimpiyatları ve Sochi (2014) Kış Olimpiyatlarında maliyet ve bütçe arasında önemli bir fark olması ve olimpiyatların oyunlarının maliyetinin beklenen ekonomik faydayı göstermemesi eleştirilere maruz kalmalarına neden olmuştur.

2012 Londra Yaz Olimpiyat Oyunlarından önce istihdam edilen kişilerin varlığı ve oyunlar sırasında çok fazla kişinin Londra'yı ziyaret etmiş olması olumlu bir etken olarak gösterilirken, olimpiyat oyunlarından sonra İngiltere'nin cazibe merkezlerinin beklenen etkiyi göstermemesi ve oyunlara göre yaz boyunca \%20 daha az ziyaretçi gelmesi olumsuz bir etken olarak ele alınmıştır. Olimpiyat oyunlarının 9,3 milyar sterlinlik kamu harcamalarının kar edip etmeyeceği konusunun tartışmalı olduğu ve son raporlarda geçici bir ekonomik durgunluğun olduğu belirtmiştir (Brown, 2012). İngiltere, Londra 2012 Olimpiyat Oyunları'nda 18 milyar \$ harcama yapmıştır ve bunun karşılığında sadece 3,5 milyar \$ gelir elde edebilmiştir (Greenberg ve MacMillian, 2018).

2014 Sochi Kış Olimpiyat Oyunları şimdiye kadar yapılan yaz ve kış olimpiyat oyunları içerisinde gerçekleştirilen en pahalı organizasyon unvanını elinde bulundurmaktadır. Sochi, 2007'de Rusya'nın olimpiyat oyunları teklifini kazanmasının ardından 12 milyar \$ olarak belirlenen bütçesinin oldukça üzerine çıkmıştır (Taylor, 2014). Olimpiyat oyunlarının maliyetleri beklenenden 4,5 kat fazla çıarak +50 milyar \$’a mal olmuştur (Müller, 2014; Golubchikov, 2017). Sochi için maliyetlerin bu kadar fazla çıkmasının pek çok faktörü vardır. Birincisi, Sochi'nin kış olimpiyat oyunları için belki de en mantıklı yer olmaması çünkü burası Rusya'nın en çok bilinen sahil beldelerinden birisidir ve etkinliklere yetecek kadar soğuk olmayacağına dair endişeler üzerine etkinliklere yetecek kadar kar olması için bazı önlemlerin alınması. İkincisi, kar temelli etkinliklere uygun olmaması ve çok inşaat masrafı gerektirmesi. Bir diğer faktör ise Rusya'nın güneyinde yaşanan terör olayları. Bu olaylar Rusya'nın güvenlik harcamalarını büyük ölçüde etkilemiştir (Taylor, 2014).

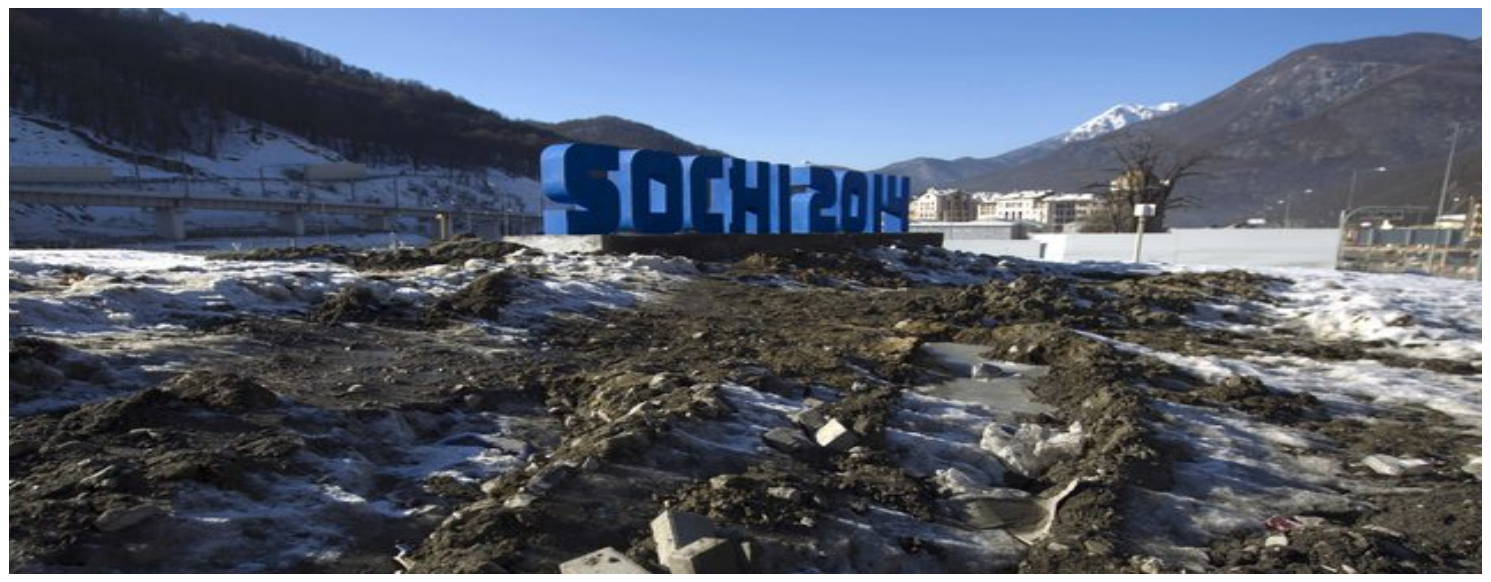

Sochi, tüm ana spor altyapısının sıfırdan yapıldığı, genel altyapı ve konaklama sektörünün tamamen yenilendiği ilk olimpiyat şehri olmuştur. Genel olarak Sochi'de 800'den fazla yapı inşa edilmiştir. Bunlardan bazıları spor tesisleri olurken diğerleri, kentsel ve bölgesel altyapının genel olarak iyileştirilmesi, elektrik santrallerinin yapılması, yeni su ve kanalizasyon sistemleri, 
telekomünikasyon ve büyük bir ulaşım ağı yapılan yatırımlardan bazılarıdır. Bunların yapılmasındaki ana amaç Sochi şehrinin dağ-iklim tatil merkezi olmasını sağlamaktır (Golubchikov, 2017). Altyapı konusunda yapılanlar daha geniş olarak Tablo 4'te verilmiştir (IOC, 2015).

Tablo 4. İnşa Edilen Yapılar

\begin{tabular}{|l|}
\hline Yeni havaalanı tesisleri \\
\hline $367 \mathrm{~km}$ yol ve köprüler \\
\hline 54 köprü ve 22 tünel ile $200 \mathrm{~km}$ demiryolu \\
\hline $697.400 \mathrm{~m}^{2}$ yol yüzeyi ve kaldırımlar \\
\hline $480 \mathrm{~km}$ düşük basınçlı gaz boru hattı \\
\hline İki termik santral ve birleşik $1200 \mathrm{MW}$ kapasiteye sahip bir gaz enerji santrali \\
\hline $550 \mathrm{~km}$ yüksek gerilim enerji hattı \\
\hline Yeni bir su ve atık arıtma tesisi \\
\hline
\end{tabular}

Kaynak: IOC, 2015

Tablo 4'te de görüldüğü üzere Sochi Kış Olimpiyat Oyunları için sıfırdan yapılmış olan yapılar oyunların maliyetinin ilk sunulan teklifin üzerinde gerçekleşmesine neden olmuştur. Ayrıca Sochi kentini bir kış turizm merkezi haline getirmek isteyen hükümet yetkililerinin, insanları buraya taşımak, ulaşım imkanlarını arttırmak, alt ve üst yapı faaliyetlerini geliştirmek adına inşa etmiş olduğu bu yapılar maliyet aşımının yaşanmasına neden olmuştur.

Rio Olimpiyatlarının kamu ve özel sektör paralarının toplamı ile birlikte 13 milyar \$'a mal olmuştur ve başlıca harcamaların, tesislerin inşasını ve altyapı çalışmalarını kapsamıştır. Olimpiyat oyunlarının kapanış seremonisinde kullanılan Maracana Olimpiyat Stadyumunun oyunlardan sonra bakımı düzgün yapılmamıştır ve kendi kaderine bırakılmıştır, hatta ödenmeyen 930 bin \$'lik fatura nedeniyle elektriğinin kesildiğini söylenmektedir (Davis, 2017; www.reuters.com). Ayrica olimpik yüzme havuzunun da oyunlar sonrasında kaderine teslim edildiği ve bakımsızlıktan dolayı renginin değiştiği söylemektedir (Burke, 2017; www.theguardian.com). Resim 1'de havuzun önceki ve sonraki hali görülmektedir.

Resim 1: Olimpiyat Havuzunun Önceki ve Sonraki Hali
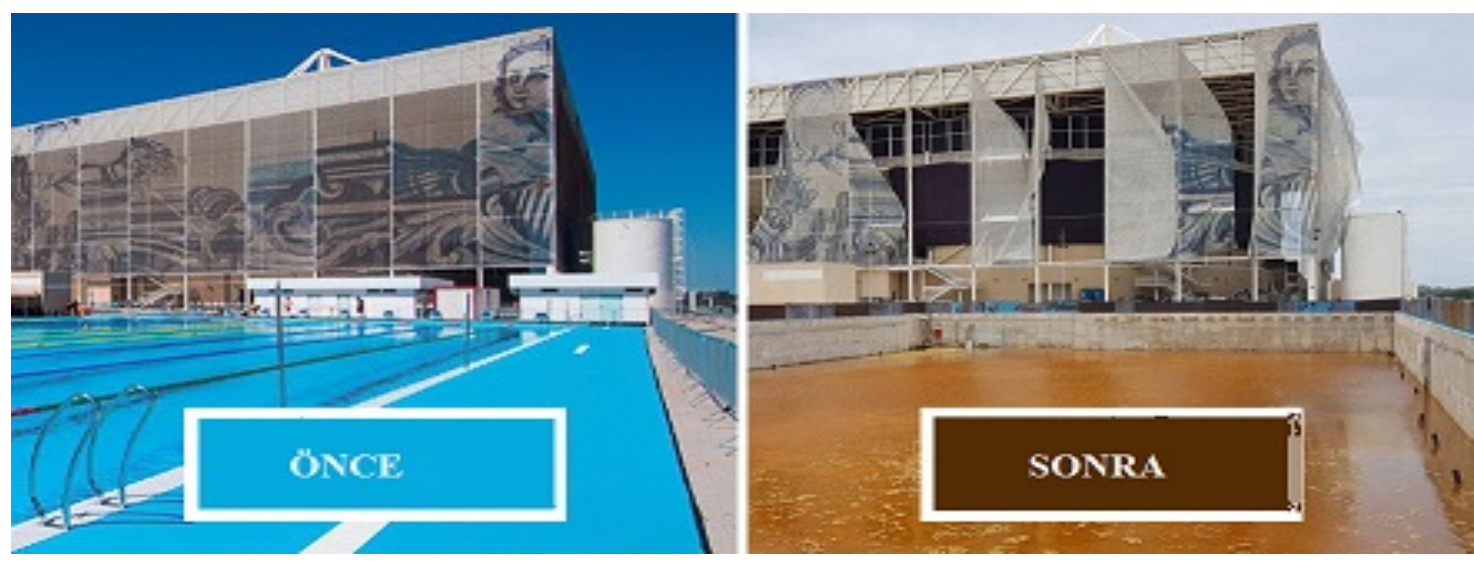

Kaynak: Castro, 2018 
Rio, olimpiyat oyunlarında sporla ilgili tesislerin, mekanların yapımı için yaklaşık 2,06 milyar \$” lık bir harcama yapmıştır (Brito ve Wade, 2017; www.usatoday.com). Fakat olimpiyat oyunlarından yaklaşık altı ay sonra yapılan birçok mekân tesis terk edilmiş, yağmalanmış ve geriye kötü bir olimpiyat mirası bırakmıştır (www.telegraph.co.uk; Davis, 2017). Olimpiyat oyunlarından altı ay sonraki bazı mekanların ve tesislerin hali ise Resim 2 ‘deki gibidir.

Resim 2: Mekanlar ve Tesisler
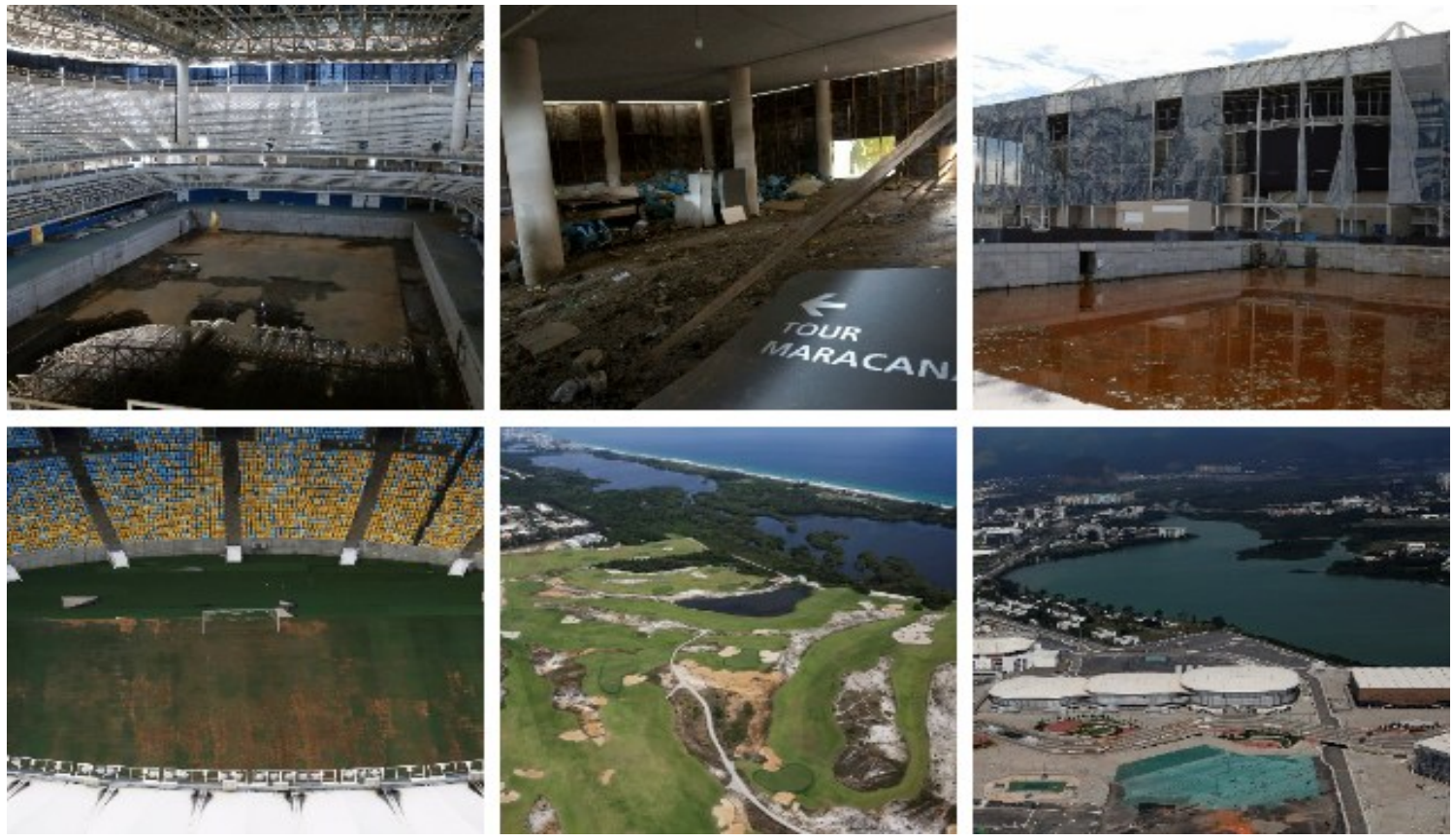

Kaynak: Telegraph, 2018

Olimpiyat oyunları için yapılan mekanların ve tesislerin teknik, yönetimsel vb. süreçlerinin yanlış planlanması sonucu oyunlar sonrasında bu alanların atıl kalması veya kullanılmaz durumda olmaları organizasyonu üstlenen devletlere fazladan maliyete sebep olmaktadır. Bu durum da olimpiyat oyunlarında yaşanan maliyet aşımlarına yol açmaktadır.

\section{SONUÇ}

Olimpiyatlar gibi büyük etkinliklere ev sahipliği yapmak organizasyonun markasının kullanılması ile ev sahibi şehre küresel anlamda saygınlığını arttırma ve uluslararası rekabette ön plana çıkma şansı verir (Rocha ve Fink, 2017). Aynı zamanda ev sahibi şehrin ekonomisinin ve altyapı hizmetlerinin iyileştirilip geliştirilmesinde önemli bir unsur olarak görülmektedir (Essex ve Chalkley, 1998; Malfas vd., 2004; Matheson ve Baade, 2004). Ancak olimpiyatlara ev sahipliği yapmış ülkelerin çoğunluğu gayrisafi yurt içi hasıla konusunda (GSYİH) sürdürülebilir bir büyüme yaşamamışlardır. Olimpiyat oyunları ev sahibi ülkelerinin GSYİH'sı genellikle oyunlardan önce yükselmiş, oyunlar başladığı sırada kaybolmaya başlamış ve daha sonra önemli ölçüde azalmıştır (Rekowsky, 2013).

Oyunları gerçekleştirmek için oldukça fazla altyapı ve tesis maliyeti gerektiren büyük bir organizasyon olan olimpiyat, yapılan harcamalar ve elde edilen gelir anlamında çoğu zaman sadece başa baş noktasına ulaşabilmiştir. Oyunların işleyişi ile ilgili olan (telekomünikasyon, teknoloji, törenler, ulaştırma vb.) yatırımlarda OCOG bütçesi kullanılsa da OCOG bütçesine ek 
olarak şehir, bölgesel veya eyalet makamları ve aynı zamanda özel sektör tarafından finanse edilen OCOG dışı bir yatırım bütçesi de bulunmaktadır. Bu yatırımlar havaalanının, yolların, konaklama yerlerinin, spor salonlarının, medya ve olimpiyat köylerinin inşasını ve yenilenmesini içerir (IOC 2010). Ev sahibi şehir bu projelerin birçoğuna yatırım yapması veya projelerin ertelenmesi ve zamanında teslim edilmemesi gibi olaylar olimpiyat oyunlarının maliyetlerinin fazla olmasına ve maliyet aşımlarının yaşanmasına neden olmaktadır (Andreff, 2016).

Olimpiyat oyunları gibi karmaşık bir etkinlik için güvenli finansal veri toplamak kolay değildir. Olimpiyat oyunları ile ilgili tüm verilerin güvenli bir şekilde toplanamamasının nedenleri ise sermaye yatırımlarının tek bir otorite tarafından yapılmaması ve hepsinin düzenli bir raporlama sisteminde görülmemesi, sermaye yatırımlarının bir kamu özel ortaklı̆̆ı olması ve özel bölümlerinin yayınlanmaması, masrafların ve gelirlerin farklı muhasebeleştirilmesi ve son olarak da yaz ve kış olimpiyat oyunlarının farklı sermaye yatırımlarına sahip olması şeklinde sıralanabilir (Preuß vd., 2019). Olimpiyat oyunlarının maliyetler ile ilgili bilgilerinin sağlıklı bir şekilde toplanamaması ve incelenen olimpiyatlarda oyunlardan sonra beklenen etkinin görülmemesi yaratılan ekonomik etkiler açısından farklı görüşlerin ortaya çıkmasına neden olmuştur.

Yapılan çalışmalara göre, olimpiyatların ekonomik etkisi aslında düzenlendiği ülkenin ekonomik ve sosyal gelişmişliği ile doğrudan ilişkilidir. Gelişmiş ekonomilerde yüksek maliyetler bu yatırımlar için çok ciddi harcamalar gerektirirken, daha az gelişmiş ekonomilerde maliyetler nispeten daha düşük olduğu için katlanılan maliyetler görece daha düşük olmaktadır. Etkinliğin getirisi açısından bakıldığında da gelişmişliğin sahip olduğu yüksek standartlar, o ekonomiyi ciddi bir getiri üstünlüğüne ulaştırırken, diğer ülkeler katlandıkları maliyetlerin üzerinde gelir yaratabilmekte zorlanmaktadırlar (Akşar, 2013). Daha az gelişmiş ülkelerin gelir yaratma anlamında zorlanmalarının sebebi ise, ülkenin turizme olan aşinalığı ve halkın turizmi ne kadar benimsediği önemli bir faktör olabilir.

Olimpiyat harcamaları, eğer ülke yüksek işsizlik oranına sahip ve ciddi ekonomik bir sıkıntının içinde bulunuyorsa, olimpiyat ev sahipliğinin o ülke ekonomisinde bir yükselişe neden olma olasılığı da yüksek görünmektedir (Ercan, 2012). Ancak, olimpiyatlarla alt yapısı ve çehresi değişen kentlerin ileriki yıllarda turizmde ciddi bir rekabet üstünlügüne ulaşma ihtimali de bulunmaktadır (1992 Barselona). Bu bağlamda yapılan altyapı iyileştirmelerinin ve tesislerin 1992 Barselona, 1996 Atlanta ve 2008 Pekin olimpiyatlarında olduğu gibi daha sonra halkın kullanımında kalacak olması da şehrin yaşam koşullarını ve cazibesini de arttırmaktadır.

Sonuç olarak olimpiyat oyunlarının olumlu ve olumsuz sonuçlarının anlaşılabilmesi ardında birçok farklı dinamikler barındırabilir. Ülkelerin gelişmişlik seviyeleri ve buna bağlı olarak turizme karşı olan tutumlarının olimpiyat oyunları üzerinde önemli bir etkisinin olduğu unutulmamalıdır. Olumlu görünen etkilerin aynı zamanda içinde olumsuz sonuçlar da barındırabileceği önemli bir sonuçtur. Bu bağlamda ileride yapılacak olan çalışmalarda araştırmacıların ülkelerin gelişmişlik seviyelerine ve turizm olanaklarına da odaklanarak bir araştırma penceresi oluşturması, geniş kapsamda olimpiyatların olumlu ve olumsuz sonuçlarının anlaşılmasına olanak sağlayabilir.

\section{KAYNAKÇA}

Ak, D. (2015). Olimpiyat oyunlarının ev sahibi kente etkileri açısından değerlendirilmesi. Pamukkale Journal of Eurasian Socioeconomic Studies, 2(1), 1-19. 
Akşar, T. (2013) Olimpiyat düzenlemek karlı bir iş mi? [Online] https://www.dunya.com/koseyazisi/olimpiyat-duzenlemek-karli-bir-is-mi/17489 [Erişim Tarihi: 20.06.2019]

Andreff, W. (2016). The Cost of Hosting International Sports Events. When Sport Meets BusinessCapabilities, Challenges, Critiques; Wagner, U., Storm, R., Nielsen, K., Eds,, 219-233.

Balmer, N., Nevill, A. and Williams, A. (2003). Modelling home advantage in the Summer Olympic Games. Journal of Sports Sciences, 21(6), 469-478.

Brito, R. and Wade, S. (2017). AP Analysis: Rio de Janeiro Olympics cost $\$ 13.1$ billion. AP News [Online] https://apnews.com/d1662ddb3bae4d2984ca4ab65012be78 [Erişim Tarihi: 13.02.2019]

Brown, M. (2012, Ekim). Were The Olympics Good Or Bad For London? Londonist [Online] https://londonist.com/2012/10/olympicsgoodbad [Erişim Tarihi: 28.01.2019]

Burke, D. (2017). Brazil's $\$ 12$ billion Olympic legacy lies in ruins: Five months after the Rio Games, stadiums are crumbling as cash-strapped nation is left with crippling debts. Dailymail [Online] https://www.dailymail.co.uk/news/article-4241412/Brazil-s-12-billion-Olympic-legacy-liesruins.html [Erişim Tarihi: 28.01.2019]

Can, E. (2015). Boş zaman, rekreasyon ve etkinlik turizmi ilişkisi. İstanbul Journal of Social Sciences(10), 1-17.

Cashman, R. (2002). Impact of the Games on Olympic host cities: university lecture on the Olympics [online article]. Barcelona: Centre d'Estudis Olimpics (UAB). International Chair in Olympism (IOC-UAB).

Castro, C. O. Rio 2016 Olympic Venues Just 6 Months After The Olympics. Boredpanda [Online] https://www.boredpanda.com/rio-olympic-venues-after-six-months/ [Erişim Tarihi: 18.12.2018]

Chalkley, B. and Essex, S. (1999). Urban development through hosting international events: a history of the Olympic Games. Planning Perspectives, 14(4), 369-394.

Davis, S. (2017). Rio's Olympic Stadium has reportedly turned into a ghost town that has a 'smell of mold,' damaged rooms, and stray cats. Business Insider [Online] https://www.businessinsider.com/rio-olympic-stadium-ghost-town-2017-1 [Erişim Tarihi: 28.01.2019]

Davis, S. (2017). The Rio Olympics were a financial disaster and it keeps getting worse. Business Insider [Online] https://www.businessinsider.com/rio-olympics-financial-disaster-2017-6 [Erişim Tarihi: 28.01.2019]

Dickson, C. and Arcodia, C. (2010). Environmentally sustainable events: a critical review of the literature. Global Events Congress IV: Festivals \& Events Research, State of the Art, Leeds Metropolitan University, 14.

Dickson, C. and Arcodia, C. (2010). Promoting sustainable event practice: The role of professional associations. International Journal of Hospitality Management, 29, 236-244.

Doralp, B. ve Barkul, Ö. (2011). Olimpiyat yerleşkeleri tasarımında bir girdi olarak sürdürülebilirlik. Megaron, 6(2), 123-137. 
Ercan, M. (2012) Olimpiyatların ekonomisi [Online] http://www.radikal.com.tr/yazarlar/metinercan/olimpiyatlarin-ekonomisi-1096866/ [Erişim Tarihi: 20.06.2019]

Erdem, Ö., Mızrak, M. ve Aratoğlu, C. (2018). Festivallerin bölge turizmine katkıları ve sürdürülebilirliği: uluslararası mengen aşçlık ve turizm festivali örneği. Journal of Tourism and Gastronomy Studies, 6(1), 228-245.

Eryılmaz, S. S. ve Cengiz, H. (2012). Mega etkinliklerin kent mekânına ekonomik yansımaları, formula 1 örneği. Sigma, 4, 77-96.

Essex, S. and Chalkley, B. (1998). Olympic Games: catalyst of urban change. Leisure Studies, 17(3), 287-206.

Factsheet Sochi 2014 Facts \& Figures. International Olympic Committee (IOC) 2015, February.

Flyvbjerg, B. and Stewart, A. (2012, June). Olympic proportions: cost and cost overrun at the Olympics 1960-2012. Saïd Business School, University of Oxford working papers, 2-23.

Getz, D. (1997). Event Management \& Event Tourism. New York: Cognizant Communication Corporation.

Getz, D. (2008). Event tourism: Definition, evolution, and research. Tourism Management, 29, 403428.

Golubchikov, O. (2017). From a sports mega-event to a regional mega-project: the Sochi winter Olympics and the return of geography in state development. International Journal of Sport Policy and Politics, 9(2), 237-255.

https://www.usatoday.com/story/sports/olympics/2017/06/14/ap-analysis-rio-de-janeiroolympics-cost-13-1-billion/102860310/ [Erişim Tarihi: 13.02.2019]

https://www.greenberglawoffice.com/cost-overruns-and-sports-venue-construction-part-2/

[Erişim Tarihi: 04.02.2019]

https://www.telegraph.co.uk/olympics/2017/02/10/wasted-legacy-rio-olympics-venues-haveallowed-descend-disrepair/ [Erişim Tarihi: 25.12.2019]

https://www.theguardian.com/sport/gallery/2017/feb/10/rios-olympic-venues-six-months-on-inpictures [Erişim Tarihi: 13.02.2019]

https://www.reuters.com/article/soccer-brazil-maracana-idUSL1N1FG16X [Erişim Tarihi: 18.02.2019]

Horne, J. D. and Manzenreiter, W. (2004). Accountıng for mega-events forecast and actual impacts of the 2002 football world cup finals on the host countries japan/korea. International revıew for the sociology of sport, 39(2), 187-203.

IOC (International Olympic Committee) 2010. Lausanne: 2018 Candidature Procedure and Questionnaire.

Kızılırmak, İ. (2006). Türkiye'de düzenlenen yerel etkinliklerin turistik çekicilik olarak kullanılmasına yönelik bir inceleme. Sosyal Bilimler Dergisi, 15, 181-196. 
Kozak, M. (2015). Bilimsel Araştırma: Tasarım, Yazım ve Yayım Teknikleri. Ankara: Detay Yayıncılık.

Malfas, M., Theodoraki, E. and Houlihan, B. (2004). Impacts of the Olympic Games as megaevents. Municipal Engineer, ME3, 209-220.

Matheson, V. A. and Baade, R. A. (2004). Mega-sportıng events in developing nations: playing the way to prosperity? The South African Journal of Economics, 72(5), 1085-1096.

Müller, M. (2014). After Sochi 2014: costs and impacts of Russia's Olympic Games. Eurasian Geography and Economics, 55(6), 628-655.

Müller, M. (2015). What makes an event a mega-event? Definitions. Leisure Studies, 34(6), 627-642.

Orttung, R. W. and Zhemukhov, S. (2014). The 2014 Sochi Olympic mega-project and Russia's political economy. East European Politics, 30(2), 175-191.

Preuß, H., Andreff, W. and Weitzmann, M. (2019). Cost and Revenue Overruns of the Olympic Games 2000-2018. Springer Fachmedien Wiesbaden GmbH.

Rekowsky, R. V. (2013). Are the Olympics a Golden Opportunity for Investors? leadership series investment insights.

Rocha, C. M. and Fink, J. S. (2017). Attitudes toward attending the 2016 Olympic Games and visiting Brazil. Tourism Management Perspectives, 22, 17-26.

Taylor, A. (2014). Why Sochi is by far the most expensive Olympics ever. Business Insider [Online] https://www.businessinsider.com/why-sochi-is-by-far-the-most-expensive-olympics-ever-20141 [Erişim Tarihi: 24.12.2018]

Tekin, A. ve Tekin, G. (2014). Antik yunan dönemi: spor ve antik olimpiyat oyunları. Tarih Okulu Dergisi (TOD)(18), 121-140.

Timur, M. N., Çevik, S. ve Kıcır, G. K. (2014). Etkinlik turizmi: kültür başkenti etkinliklerinin başarı unsurları üzerine bir değerlendirme. Akademik Sosyal Araştırmalar Dergisi, 2(1), 56-83.

Yıldız, E. ve Aydın, S. A. (2013). Olimpiyat Oyunlarının Sürdürülebilir Kalkınma Açısından Değerlendirilmesi. Spor Bilimleri Dergisi, 24(4), 269-282.

Zimbalist, A. (2010). Is It Worth It ? Finance \& Development, 8-11. 